\title{
Diabetic autonomic neuropathy and iritis: an association suggesting an immunological cause
}

\author{
R J C GUY, F RICHARDS, M E EDMONDS, P J WATKINS
}

\begin{abstract}
Of 47 insulin requiring diabetics aged 21-40 years with autonomic neuropathy (heart rate variability $<10$ ), 14 had previously developed iritis. In all except two cases the iritis preceded the autonomic symptoms. The autonomic neuropathy was very severe, 10 patients having two or more characteristic symptoms. Ten of the patients with iritis were women.

The association of iritis (itself an immune disorder) with severe symptomatic autonomic neuropathy raises the possibility of an underlying immunological basis for autonomic neuropathy.
\end{abstract}

\section{Introduction}

Autonomic neuropathy together with loss of pain and temperature sensation results from damage to small unmyelinated nerve fibres. Diabetes is the most common disease causing this type of peripheral neuropathy, but it occurs in other rare neuropathies, notably amyloid. ${ }^{1}$ Like diabetes, leprosy and syphilis are also associated with a destructive neuroarthropathy ("Charcot's joints"), probably as the consequence of combined autonomic damage and loss of pain sensation. ${ }^{2}$ In addition, syphilis and some forms of leprosy are associated with iritis, and we describe the occurrence of iritis in patients with severe diabetic autonomic neuropathy. Iritis is known to be associated with immunologically mediated disorders, leading to speculation that autonomic neuropathy may have an immunological basis. ${ }^{3}$

King's College Hospital, London SE5 9RS

R J C GUY, MA, MRCP, research fellow, diabetic department F RICHARDS, FRCS, senior registrar, department of ophthalmology

M E EDMONDS, MRCP, lecturer, diabetic department

P J WATKINS, MD, FRCP, consultant physician, diabetic department

Correspondence to: Dr R J C Guy.

\section{Patients and methods}

We studied all patients aged 40 or less who were known to have diabetic autonomic neuropathy, as defined by a heart rate variability of less than 10. A control group of patients of similar age and duration of diabetes without symptomatic autonomic neuropathy were also studied. All were insulin requiring.

To determine if any patient had had iritis each was asked whether they had ever had hospital treatment for a painful eye and whether they had had iritis. An affirmative answer to either question was followed up by contacting the ophthalmologist who initiated treatment and a diagnosis of iritis accepted only if made by the ophthalmologist on the basis of symptoms of pain and photophobia and evidence of flare and cells in the anterior chamber.

Patients who had had iritis in the past were examined by an ophthalmologist for causes and sequelae of iritis. HLA tissue typing was performed by established methods. ${ }^{56}$ Non-organ-specific antibodies were measured by standard techniques and syphilitic serology by Venereal Disease Research Laboratory and rapid plasma reagin tests.

Heart rate variability was measured at 6 breaths $/ \min ^{7}$ using a Lectromed rate meter, $M X 2 P$ amplifier, and $M X 212$ chart recorder.

Autonomic symptoms were defined as follows: diabetic diarrhoeaintermittent and especially nocturnal diarrhoea, usually with faecal incontinence and preceded by borborygmi with no other gastrointestinal disease; bladder paresis-delayed micturition with a residual volume on either intravenous urography or bladder ultrasound with no mechanical obstruction; postural hypotension-hypotensive symptoms on standing with a drop of $30 \mathrm{~mm} \mathrm{Hg}$ or more in systolic blood pressure; gastroparesis - recurrent vomiting with residual fluid and food after an overnight fast and delayed transit of barium on barium meal and videotape analysis, no mechanical obstruction being seen on gastroscopy; gustatory sweating - facial sweating precipitated by eating specific foods, especially cheese or yoghurt. In addition, a Charcot joint was defined as a fracture of bone with subsequent disorganisation of joint surfaces leading to bony deformity in the foot.

\section{Results}

Of the 57 patients ( 33 women, 24 men) known to have a heart rate variability of $<10$ and seen during the previous eight years, 45 replied to the questionnaire, six did not reply, and six had died. Full details including ophthalmic records were available on two of the patients who had died and who had had iritis, and these are included in the iritis group. Details were therefore available for 47 patients (table I). 
TABLE I-Details of patients

\begin{tabular}{lcc}
\hline & $\begin{array}{c}\text { Autonomic } \\
\text { neuropathy }\end{array}$ & $\begin{array}{c}\text { Diabetics without } \\
\text { autonomic } \\
\text { neuropathy }\end{array}$ \\
\hline No (and sex) & 47 (M 20, F 27) & $143(\mathrm{M} \mathrm{67,} \mathrm{F} \mathrm{76)}$ \\
Mean age in years (range)* & $33 \cdot 6(21-40)$ & $31.3(17-39)$ \\
Mean duration of diabetes in years (range)* & $20 \cdot 8(9-34)$ & $17 \cdot 7(9-36)$ \\
No with iritis & $14 \dagger$ & $1 \dagger$ \\
\hline
\end{tabular}

* Age and duration of disease taken at time of death in two patients

$+x^{2}=31.298 ; \mathrm{p}<0.001$.

Of the 47 patients with autonomic neuropathy, 14 had had iritis in the past. The iritis group comprised 10 women and four men and the non-iritis group 17 women and 16 men. Table II gives details of their age and duration of diabetes.

TABLE II-Details of patients with autonomic neuropathy

\begin{tabular}{lcc}
\hline & Iritis group & Non-iritis group \\
\hline No (and sex) & $14(\mathrm{M} \mathrm{4}, \mathrm{F} \mathrm{10})$ & $33(\mathrm{M} 16, \mathrm{~F} 17)$ \\
Mean age in years (range)* & $31 \cdot 2(22-40)$ & $34 \cdot 6(21-40)$ \\
Mean duration of diabetes in years (range)* & $16 \cdot 7(9-25)$ & $22.5(10-34)$ \\
\hline
\end{tabular}

*Age and duration of disease taken at time of death in two patients

The control group of insulin requiring diabetics with no symptoms of autonomic neuropathy consisted of 143 patients of similar age range and duration of diabetes (table I); only one of them had had iritis, and this was associated with Reiter's disease.

The iritis was bilateral in 11 patients, all of whom had further episodes, while of three who had a unilateral episode there was a recurrence in only one case. Treatment was always by an ophthalmologist and consisted of steroid eye drops in every case and mydriatics in 12 cases. At the time of diagnosis and subsequent follow up no known cause of the iritis had been found. In particular, there was no evidence of rubeosis iridis.

Table III shows the severity and details of the autonomic neuropathy. Of the 14 patients with iritis, 10 had two or more characteristic symptoms of autonomic neuropathy and seven also had a Charcot joint, representing a severe peripheral sympathetic neuropathy with pain loss. The heart rate variability was noticeably abnormal in all cases. In the non-iritis group eight out of 33 patients had two or more classic symptoms and four had a Charcot joint.

TABLE III-Details of autonomic neuropathy

\begin{tabular}{lcc}
\hline & $\begin{array}{c}\text { Iritis group } \\
(\mathrm{n}=14)\end{array}$ & $\begin{array}{c}\text { Non-iritis group } \\
(\mathrm{n}=33)\end{array}$ \\
\hline Mean heart rate variability (range) & $3 \cdot 4(0-8 \cdot 5)$ & $5 \cdot 0(0-9 \cdot 7)$ \\
Nowith: & 9 & 5 \\
Postural hypotension & 6 & 12 \\
Gustatory sweating & 7 & 12 \\
Diabetic diarrhoea & 5 & 3 \\
Bladder paresis & 1 & 1 \\
Gastroparesis & 10 & 8 \\
No with two or more characteristic symptoms & 7 & 4 \\
No with Charcot's joints & &
\end{tabular}

The iritis preceded the autonomic symptoms in all cases except two by a range of six to 60 months. The mean age at diagnosis of the first episode of iritis was 24.9 years (range 17-34) and the mean duration of diabetes at the time was 10.5 years (range 6-20). Two patients developed iritis 24 and 30 months respectively after their autonomic symptoms appeared. The eyes of all 12 living patients with iritis were re-examined by an ophthalmologist. Proliferative retinopathy was present in seven, background retinopathy in three, and no retinopathy in two. There was no evidence of rubeosis or posterior synechiae in any case.

Venereal Disease Research Laboratory and rapid plasma reagin tests gave negative results in all patients. Non-organ-specific autoantibodies were present in a significant titre in one case only to gastric parietal cells at a dilution of $1 / 160$. Examination of HLA state showed that only one was B27 among the nine patients studied.
DR typing showed five to be DR3 or 4, consistent with insulin dependent diabetes. In the four others DR typing was not possible despite repeated attempts.

\section{Discussion}

Although over 100 years ago Noyes suggested that diabetes caused iritis $^{8}$ and Whittington and Lawrence described a particular type of iritis associated with diabetes, ${ }^{9}$ there was no suggestion that iritis was linked with diabetic autonomic neuropathy. We have described the presence of iritis in nearly one third of our most severe cases of autonomic neuropathy, suggesting an association between these two conditions. The iritis in all but two cases preceded the first appearance of autonomic symptoms. Interestingly, seven of these patients also had Charcot's joints, otherwise rare and probably another consequence of autonomic neuropathy (sympathetic failure) combined with loss of pain sensitivity. ${ }^{2}$ The association of iritis-itself an immunologically mediated disorder with circulating immune complexes ${ }^{10-12}$-with the small fibre damage which results in autonomic neuropathy leads to speculation that autonomic damage may also have an immune basis.

Further evidence of an immune basis for autonomic neuropathy came from the postmortem studies of Duchen et al on five of our patients with severe autonomic neuropathy, ${ }^{13}$ one of whom was included in the present study having had iritis. Inflammatory cellular infiltrations of lymphocytes, macrophages, and occasionally plasma cells were found, particularly related to autonomic nerve bundles and ganglia, in or around bundles of unmyelinated nerve fibres and in the superior cervical sympathetic ganglion.

A hypothesis for a possible mechanism is that insulin antibodies may cross react with nerve growth factor and cause sympathetic nerve damage. Nerve growth factor ${ }^{14}$ is important for the growth $^{15}$ and survival ${ }^{16}$ of sympathetic nerves in experimental models. Antibodies to nerve growth factor damage sympathetic nerves, and their long term presence in the circulation causes a pronounced atrophy of the superior cervical ganglion in adult rats. ${ }^{17}$ Nerve growth factor has some structural similarities to insulin in its amino acid sequence ${ }^{18}$ and predicted secondary ${ }^{19}$ and tertiary ${ }^{20}$ structure. Since nerve growth factor and insulin may therefore share similar antigenic determinants, insulin antibodies might have a similar action to nerve growth factor antibodies and damage sympathetic nerves. Moreover, although nerve growth factor is not present in adult rat irises, sensory or sympathetic denervation leads to rapid accumulation of the factor in the iris. ${ }^{21}$ In autonomic neuropathy the nerve growth factor that might accumulate there may cross react with insulin antibodies and also lead to immune complex formation and iritis.

Diabetic autonomic neuropathy appears to be associated with iritis, suggesting that both may be due to immunological damage. This might result from a cross reaction of insulin antibodies and nerve growth factor. Future investigations of these patients will examine these complex immunological phenomena.

We thank Dr D A Pyke and Mr E W G Davies for their help and encouragement and Dr E Wolf, of St Bartholomew's Hospital Medical College, for performing the HLA tissue typing. RJCG is supported by a research grant from Pfizer Ltd.

\section{References}

'Rubenstein AE, Rudansky MC, Yahr MD. Autonomic failure due to amyloid. In: Bannister R, ed. Autonomic failure. A textbook of clinical disorders of the In: Bannister R, ed. Autonomic failure. A textbook of clinical disorders of the
autonomic nervous system. Oxford: Oxford University Press, 1982:574-95. Watkins PJ, Edmonds ME. Autonomic neuropathy: blood flow in the diabetic foot. In: Skandia international symposia. Recent trends in diabetic research. Stockholm: Almqvist and Wiksell International, 1982:211-9.

Bannister R, ed. Introduction and classification. In: Autonomic failure. A textboo of clinical disorders of the autonomic nervous system. Oxford: Oxford University Press, 1982:8. 

' Bennet T. Physiological investigation of diabetic autonomic failure. In: Bannister
R, ed. Autonomic failure. A textbook of clinical disorders of the autonomic nervous $\mathrm{R}$, ed. Autonomic fallure. A textbook of clinical disorders
system. Oxford: Oxford University Press, 1982:408-9.

system. Oxford: Oxford University Press, 1982:408-9. Wolf E. The distribution of HL-A antigens in expatriates from east Bengal living in London. In: Dausset $\mathrm{J}$, Colombani J, eds. Histocompatibility testing. Copenhagen: Munksgaard, 1972:175-8.

Van Rood JJ, van Leeuwen A, Ploem JS. Simultaneous detection of two cell populations by two-colour fluorescence and application to the recognition of B cell determinants. Nature 1976;262:795-7.

Mackay JD, Page MMcB, Cambridge J, Watkins PJ. Diabetic autonomic neuropathy: the diagnostic value of heart rate monitoring. Diabetologia 1980;

$18: 471-8$.
Noyes HD. Retinitis in glycosuria. Transactions of the American Ophthalmological Society 1868:71-5.

hittington TD, Lawrence TD. Metabolic disorders. Diabetes mellitus. In: Sorsby A, ed. Systemic ophthalmology. London: Butterworth \& Co, 1951: 334-48.

" Wong VG, Anderson RR, McMaster PRB. Endogenous immune uveitis: the role of serum sickness. Arch Ophthalmol 1971;85:93-102.

Howes EL, McKay, DG. Circulating immune complexes. Effects on ocular vascular permeability in the rabbit. Arch Ophthalmol 1975;93:365-70.

Dernouchamps JP, Vaerman JP, Michiels J, Masson PL. Immune complexes in the aqueous humor and serum. Am $\mathcal{F}$ Ophthalmol 1977;84:24-31.
${ }^{3}$ Duchen LW, Anjorin A, Watkins PJ, Mackay JD. Pathology of autonomic neuropathy in diabetes mellitus. Ann Intern Med 1980;92:301-3.

Cohen S, Levi-Montalcini R, Hamburger V. A nerve growth stimulating factor isolated from sarcomas 37 and 180. Proc Natl Acad Sci USA 1954;40:1014-8. Levi-Montalcini R, Angeletti PU. Nerve growth factor. Physiol Rev 1968;48: 534-69.

${ }^{16}$ Levi-Montalcini R, Booker B. Destruction of the sympathetic ganglia in mammals by an antiserum to the nerve-growth promoting factor. Proc Natl Acad Sci USA

: Gorin PD, Johnson EM. Effects of long-term nerve growth factor deprivation on the nervous system of the adult rat: an experimental autoimmune approach Brain Res 1980;198:27-42.

${ }^{8}$ Frazier WA, Angeletti RH, Bradshaw RA. Nerve growth factor and insulin: Wral similarities indicate an evolutionary relationship reflected by physiological action Science 1972;176:482-8.

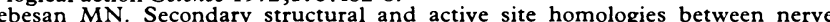

growth factor and insulin. F Theor Biol $1980 ; 83: 469-76$.
20 Frazier WA, Hogue-Angeletti RA, Sherman R, Bradshaw RA. Topography of mouse $2.5 \mathrm{~S}$ nerve growth factor. Reactivity of tyrosine and tryptophan. Biochemistry 1973;12:3281-93.

"1 Ebendal T, Olson L, Seiger $\AA$, Hedlund K-O. Nerve growth factors in the rat iris. Nature 1980;286:25-8.

(Accepted 9 May 1984)

\title{
Risk of minor and major fetal malformations in diabetics with high haemoglobin $A_{1 c}$ values in early pregnancy
}

\author{
K YLINEN， P AULA， U-H STENMAN， T KESÄNIEMI-KUOKKANEN， K TERAMO
}

\begin{abstract}
Maternal haemoglobin $A_{1 c}\left(H b A_{1 c}\right)$ values were measured before the end of the 15th week of gestation in 142 pregnancies in women with insulin dependent diabetes. In pregnancies complicated by fetal malformations (n 17) the mean initial $\mathrm{HbA}_{1 \mathrm{c}}$ value was 9.5 (SD 1.8)\% of the total haemoglobin concentration, which was significantly $(p<0.001)$ higher than in pregnancies without malformations (8.0 (SD 1.4)\%; $n=125)$. $\mathrm{HbA}_{\mathrm{lc}}$ values did not differ between pregnancies complicated by minor and major fetal malformations, but the rate of malformations showed a positive relation to the $\mathrm{HbA}_{\mathrm{lc}}$ value in early pregnancy $\left(\chi^{2}=11.9 ; \mathbf{p}=0.001\right)$. Fetal malformations occurred in six out of 17 pregnancies $(35.3 \%)$ in mothers whose initial $\mathbf{H b A}_{1 c}$ value was $10 \%$ or more, in eight out of 62 pregnancies $(12.9 \%)$ in mothers with initial values between $8.0 \%$ and $9.9 \%$, and in only three out of 63 pregnancies $(4.8 \%)$ in mothers with an initial value below $8.0 \%$.

These data support the hypothesis that the increased incidence of fetal malformations in mothers with insulin dependent diabetes is associated with maternal hyperglycaemia during organogenesis. Hence diabetic women who are planning to have a child-especially those with a high $\mathrm{HbA}_{1 \mathrm{c}}$ value-should receive intensified metabolic control.
\end{abstract}

\section{Introduction}

The incidence of congenital malformations is about three times higher in infants of insulin dependent diabetic mothers

\footnotetext{
First and Second Departments of Obstetrics and Gynaecology, Helsinki University Central Hospital, 00290 Helsinki 29, Finland $K$ YLINEN, MD, resident

P AULA, MD, medical geneticist

U-H STENMAN, MD, head, clinical laboratory

T KESÄNIEMI-KUOKKANEN, research assistant

$\mathrm{K}$ TERAMO, MD, obstetrician and perinatologist

Correspondence to: Dr K Teramo.
}

than in the general population. ${ }^{1}$ During recent years a dramatic decrease in both perinatal mortality and neonatal morbidity has occurred as a result of intensive treatment of diabetes during pregnancy. The incidence of congenital malformations, however, has remained essentially the same. ${ }^{2}$ The exact cause of this increase in malformations in diabetic pregnancies is not known, but experimental ${ }^{3}$ and clinical data ${ }^{4}$ show an association between congenital malformations and maternal hyperglycaemia in early pregnancy-the critical period with regard to fetal malformations. ${ }^{5}$

We report an association between the severity of maternal hyperglycaemia in early pregnancy as measured by blood haemoglobin $A_{1 c}\left(\mathrm{HbA}_{1 c}\right)$ values and the occurrence of fetal malformations in mothers with insulin dependent diabetes.

\section{Patients and methods}

Between April 1978 and December 1982 the maternal $\mathrm{HbA}_{1 \mathrm{c}}$ value had been determined at least once before the end of the 15 th week of gestation in 139 insulin dependent diabetic patients who gave birth after 24 weeks of gestation. Four of them had a twin pregnancy. In addition, a fetal malformation was observed in three cases of induced abortion where an early $\mathrm{HbA}_{1 \mathrm{c}}$ determination had been carried out. In two of these cases preoperative ultrasound had detected the malformation. These cases were also included in the study, so that the total number of pregnancies was 142 and the total number of fetuses 146. The maternal diabetes was classified according to White, as modified by Pedersen.$^{6}$ Thirty eight pregnancies were in women with class B disease, 45 in women with class $C$ disease, 49 in women with class D disease, and 10 in women with class $F$ disease. The mean maternal age at delivery was 27.3 years (range 19-39).

Principles of the management of pregnancy and delivery of insulin dependent diabetics at this hospital have been described. ${ }^{7}$ The patients were referred to the hospital between the sixth and 15th weeks of gestation and kept under the care of a specialist team of obstetricians and internists. Ultrasound examinations were performed to determine gestational age, number of fetuses, and fetal morphology and to monitor intrauterine growth. The infants were examined physically by neonatologists at least three times: at birth, at the age of 1 day, and on discharge from the hospital (not before seven days). If a congenital defect was found or suspected further diagnostic studies were carried out when necessary. Pregnancies were classified as $(a)$ not complicated by malformation, $(b)$ complicated by minor 